\title{
Pilot study of a ketogenic diet in relapsing- remitting MS
}

J. Nicholas Brenton, MD, Brenda Banwell, MD, A.G. Christina Bergqvist, MD, Diana Lehner-Gulotta, RDN, CNSC, Lauren Gampper, BA, Emily Leytham, BA, Rachael Coleman, MPH, and Myla D. Goldman, MD, MSc

Neurol Neuroimmunol Neuroinflamm 2019;6:e565. doi:10.1212/NXI.0000000000000565

\section{Abstract}

\section{Objective}

To assess the safety and tolerability of a modified Atkins diet $\left(\mathrm{KD}^{\mathrm{MAD}}\right)$, a type of ketogenic diet (KD), in subjects with relapsing MS while exploring potential benefits of KDs in MS.

\section{Methods}

Twenty subjects with relapsing MS enrolled into a 6-month, single-arm, open-label study of the $\mathrm{KD}^{\mathrm{MAD}}$. Adherence to $\mathrm{KD}^{\mathrm{MAD}}$ was objectively monitored by daily urine ketone testing. Fatigue and depression scores and fasting adipokines were obtained at baseline and on diet. Brain MRI was obtained at baseline and 6 months. Intention to treat was used for primary data analysis, and a per-protocol approach was used for secondary analysis.

\section{Results}

No subject experienced worsening disease on diet. Nineteen subjects (95\%) adhered to $\mathrm{KD}^{\mathrm{MAD}}$ for 3 months and 15 (75\%) adhered for 6 months. Anthropometric improvements were noted on $\mathrm{KD}^{\mathrm{MAD}}$, with reductions in body mass index and total fat mass $(p<0.0001)$. Fatigue $(p=$ $0.002)$ and depression scores $(p=0.003)$ were improved. Serologic leptin was significantly lower at 3 months $(p<0.0001)$ on diet.

\section{Conclusions}

$\mathrm{KD}^{\mathrm{MAD}}$ is safe, feasible to study, and well tolerated in subjects with relapsing $\mathrm{MS}$. $\mathrm{KD}^{\mathrm{MAD}}$ improves fatigue and depression while also promoting weight loss and reducing serologic proinflammatory adipokines.

\section{Classification of evidence}

The study is rated Class IV because of the absence of a non-KD control group.
Correspondence

Dr. Brenton

jnb8h@virginia.edu

\section{MORE ONLINE}

$\rightarrow$ Class of Evidence

Criteria for rating

therapeutic and diagnostic

studies

NPub.org/coe 


\section{Glossary}

BDI = Beck Depression Inventory; BHB = beta-hydroxybutyrate; BMI = body mass index; EAE = experimental autoimmune encephalitis; EDSS = Expanded Disability Status Scale; KD = ketogenic diet; MIFS = Modified Fatigue Impact Scale; PASAT = Paced Auditory Serial Addition Test; RRMS = relapsing-remitting MS; SDMT = Symbol Digit Modalities Test.

Obesity is a recognized risk factor for MS, ${ }^{1}$ and dietary intake is one potentially modifiable environmental contributor to MS that has garnered much interest from people living with MS. ${ }^{2}$ Furthermore, diet-as a modifier of disease progression-is supported by recent work providing an independent, epidemiologic association between dietary habits and level of sustained disability. ${ }^{3}$ Moreover, diet quality and an active lifestyle were also associated with reduced levels of fatigue, depression, pain, and cognitive impairment. ${ }^{3}$ Several diets have been popularized within the MS community, but formal studies with scientific evidence are lacking to support the use of a particular diet therapy.

Ketogenic diets (KDs) are high-fat, low-carbohydrate diets that mimic a fasting state. KDs create a metabolic shift from glycolytic energy production toward oxidative phosphorylation energetics by using fatty acids as a primary source of energy. As these fatty acids undergo beta-oxidation, ketones are produced. This increase in oxidative phosphorylation coupled with ketone production modifies the tricarboxylic acid cycle to limit reactive oxygen species generation. In addition, ketone bodies transported across the blood-brain barrier upregulate antioxidant pathway genes (particularly via the Nrf2 pathway) and boost energy production in brain tissue. ${ }^{4-7}$ Most importantly, KDs have been shown in multiple, recent animal and human studies to attenuate biomarkers of inflammation within the blood and CSF. ${ }^{8-12}$ One mechanism for its anti-inflammatory effects is via production of betahydroxybutyrate (BHB), a ketone body that blocks the NLRP3 inflammasome and reduces proinflammatory cytokine production (notably, IL-1 $\beta$ ) by human monocytes. ${ }^{8,913-15}$ Preclinical studies have assessed the benefits of the $\mathrm{KD}$ in the experimental autoimmune encephalitis (EAE) mouse model of MS. EAE mice fed a $\mathrm{KD}$ experienced several positive effects including reversed motor disability, improved spatial learning and memory, increased hippocampal volumes, and remyelination of periventricular lesions. These benefits were associated with suppressed production of inflammatory cytokines and enhanced neuronal repair. ${ }^{10}$

Collectively, animal model data are supportive, but insufficient, to suggest that a $\mathrm{KD}$ may modify an individual's immune response, thereby altering MS disease course within a human population. KDs, in particular, may alter key aspects of MS pathogenesis via ketosis-induced upregulation of antioxidant pathways, reduced effector cell immunity, and enhanced CNS bioenergetics, which may provide an alternative energy source to vulnerable neurons. In light of these promising animal data, our group sought to assess the safety and tolerability of a $\mathrm{KD}$ in a relapsing-remitting MS (RRMS) population.

\section{Methods}

\section{Subjects/recruitment}

Twenty subjects with a diagnosis of RRMS per McDonald 2010 criteria $^{16}$ were enrolled into a 6-month, single-arm, uncontrolled, open-label pilot study examining the feasibility, safety, tolerability, and efficacy of a type of $\mathrm{KD}$ - the modified Atkins diet $\left(\mathrm{KD}^{\mathrm{MAD}}\right)$. This study provides Class IV evidence of this primary research aim. To be eligible for inclusion, subjects had to be aged between 15 and 50 years, seen and treated in the University of Virginia (UVA) MS Clinic, and maintained on disease-modifying therapy. In addition, subjects had to exhibit disease stability, which was defined by both (1) the absence of clinical relapse and (2) absence of new/ enlarging T2 or gadolinium-enhancing lesions on MRI for at least 12 months before study enrollment. Subjects were excluded from the study if they had an Expanded Disability Status Scale (EDSS) score of $>6.0$, history of known cardiovascular or renal disease, currently were pregnant or were planning pregnancy, or had a body mass index (BMI) of $<20$ $\mathrm{kg} / \mathrm{m}^{2}$ for adults or $<10$ th percentile $\mathrm{e}^{17}$ for those aged younger than 18 years.

Eligible study subjects were identified through our MS clinical database and contacted via a mailed recruiting advertisement. The mailing was sent to 150 subjects, meeting the eligibility criteria for this study. When a subject expressed interest, they were provided our study objectives, parameters, diet specifics, and study design. Those who remained committed to the study completed a screening assessment to confirm eligibility.

\section{Standard protocol approvals, registrations, and subject consents}

The study was approved by the University of Virginia Institutional Review Board for Health Sciences Research, and all subjects provided informed consent (and assent when applicable) before conducting any study-related procedures.

\section{Study procedures}

At the baseline visit, demographic information was collected, including age, race/ethnicity, sex, weight, height, and waist circumference. Medical history and history of previous/ current diet attempt(s) were reviewed and documented by both subject report and medical records. MS-related data collection included history of relapses, past/current diseasemodifying therapies, and disease duration. 


\section{Anthropometric measures}

Body size and composition were used as indicators of growth and nutritional status. Weight was measured on an electronic ScaleTronix digital scale (accurate to $0.1 \mathrm{~kg}$ ), stature (accurate to $0.1 \mathrm{~cm}$ ) measured on a stadiometer, and waist circumference measured with a nonstretchable plastic tape. All measurements were recorded at baseline and at each follow-up visit. As a measure of body composition, subjects underwent body mass assessment via air displacement plethysmography (BOD POD; COSMED, Rome, Italy) that uses whole-body densitometry to determine body composition (fat vs lean). BOD POD measurements were obtained at baseline and 6 months on diet to determine body composition change secondary to our diet intervention.

\section{Diet intervention}

At the baseline visit, subjects met with our study dietitian (D.L.G.), with specialized expertise in KDs, for nutrition preassessment before diet start. The dietitian provided a personalized educational session on initiation and maintenance of a $\mathrm{KD}^{\mathrm{MAD}}$. The $\mathrm{KD}^{\mathrm{MAD}}$ is a type of $\mathrm{KD}$ that allows more flexibility and relatively high levels of ketosis by restricting carbohydrates to $<20 \mathrm{~g}$ per day and encouraging greater fat intake, with virtually all subjects reaching some degree of ketosis. ${ }^{18}$ On completion of baseline teaching, the dietitian provided contact information so that subjects could use her as a resource outside of study visits. The dietitian met with study subjects at 1-month, 3-month, and 6-month follow-up study visits. At the end of the 6-month diet trial, the dietitian provided all subjects with a plan to wean safely from $\mathrm{KD}^{\mathrm{MAD}}$.

\section{MRI}

After enrollment, all subjects underwent a protocolized 3-Tesla clinical MRI of the brain with contrast to evaluate the number of FLAIR/T2 hyperintensities. Imaging was repeated at 6 months on diet to assess for the number of new or newly enlarged T2 lesions and/or contrast-enhancing lesions (CELs). Imaging studies for all subjects were performed on the same MRI research scanner. Imaging studies were reviewed and interpreted by a trained neuroradiologist. These studies were also independently reviewed by the study primary investigator (J.N.B.).

\section{Clinical and subject-reported outcome measures}

At the baseline visit, all subjects had a formal EDSS assessment completed by a single investigator (J.N.B.-a Neurostatus-certified examiner). In addition, all subjects underwent testing with the Multiple Sclerosis Functional Composite-a composite disability measure of ambulation (timed 25-foot walk), arm function (Nine-Hole Peg Test), and cognition (Paced Auditory Serial Addition Test [PASAT]). Subjects completed the Symbol Digit Modalities Test (SDMT), which serves as an objective measure of visuospatial processing speed. Finally, all subjects underwent a 6-minute walk (6MW) assessment, which is a validated outcome measure of physical disability that measures the total distance walked in a timed 6 minutes.

Subject-reported fatigue was measured by the Modified Fatigue Impact Scale (MFIS), a 21-question survey that provides an assessment of the effects of fatigue in terms of physical, cognitive, and psychosocial functioning. Subject-reported depression was assessed by the Beck Depression Inventory (BDI) 1A, a 21-item inventory that measures attitudes and symptoms of depression.

\section{Blood studies}

Subjects underwent fasting, early morning serum sampling before diet start, and at 3 and 6 months on diet. The laboratory evaluation included blood glucose, insulin, hemoglobin A1c, lipid profile (low-density lipoprotein [LDL], high-density lipoprotein, triglycerides, and cholesterol), 25-hydroxyvitamin $\mathrm{D}$, bicarbonate, and liver function. The majority of subjects were already taking supplemental vitamin $\mathrm{D}$ at various doses recommended from their outpatient neurologist. Vitamin D supplementation was continued as advised, and doses were not altered during the course of this study. Finally, fasting serologic adipokines (leptin and adiponectin) were assessed by ELISA, manufactured by Millipore.

Once enrolled, subjects were evaluated at baseline and 1, 3, and 6 months on diet. There was a final follow-up visit 3 months after study completion to assess current dietary habits, subject-reported outcomes, and anthropometric measures. As an objective marker of diet compliance, subjects were provided with urine ketone test strips for 6 months. The subject was advised to urinate into a cup and dip the test strip into the urine. The test strip then changes color to reflect the level of ketosis (negative, trace, small, moderate, large, and very large). All subjects were required to take daily, dated pictures of their test strips and email these pictures as objective evidence of ketosis (i.e., "adherence") throughout the 6-month study period. Subjects were considered adherent to the diet if they achieved some level of ketosis for that day (e.g., trace ketones or higher). A negative ketone strip or a day without dated, photographic evidence of ketosis were considered nonadherent days. Compliance with this diet was defined a priori as $>85 \%$ compliant days out of the 6 -month study period. Any subject who was lost to follow-up before the 6-month visit was counted as a nonadherent subject. Once a subject was lost to follow-up, subsequent missing data were excluded in the clinical and laboratory data reporting.

\section{Statistical analysis}

All statistical analyses were conducted using SAS 9.4 software. This was a pilot study with no previous sample size calculation and thus no correction for multiple comparisons. For primary data analysis, an intention-to-treat approach was used; thus, the data from all subjects completing the 3-and 6-month time points were included. As a secondary sensitivity analysis, a per-protocol approach was used to study the group of those 
individuals who successfully met study compliance requirements for the diet intervention. All descriptive statistics were calculated and reported using standard appropriate statistics (e.g., means, frequencies, and t-statistic). Paired $t$ tests and $\chi^{2}$ tests were used as appropriate for continuous and categorical variables to provide in-group comparisons from baseline to 3 and 6 months on diet. Spearman correlation coefficients were used to assess the relationship between change in leptin and BMI. A 2-sided $p$ value of $<0.05$ was defined as statistically significant.

\section{Data availability}

Any data not published within the article are available, and the anonymized data will be shared by request from any qualified investigator.

\section{Results}

\section{Study subject demographics}

From a mailing sent to 150 eligible subjects, 51 subjects responded with interest. From these 51 responders, the first 20 to respond were enrolled into the study. A single subject declined enrollment on hearing the study details, and a single subject was excluded because of a BMI of $<20 \mathrm{~kg} / \mathrm{m}^{2}$ at the time of enrollment. The remainder of interested subjects $(\mathrm{n}=$ 29) were placed on a wait list for future study opportunities.

Baseline study subject demographics are detailed in table 1. The cohort's median age was 38 years (range: $15-50$ years) with an average disease duration of 9.5 years. Ninety-five percent of the cohort was either overweight or obese by the Centers for Disease Control and Prevention criteria, ${ }^{17}$ and more than half of the subjects had attempted dietary changes before this study, specifically for the purposes of improving MS.

\section{Adherence to KD ${ }^{\text {MAD }}$}

Among the 20 subjects, 2 were lost to follow-up. Before being lost to follow-up, the first subject had complied with 1 month of diet, and the second had complied with 3 months of diet. Of the remaining 18 subjects, 15 (75\%) met the study's criteria for "adherence" as defined by demonstrating urinary ketosis for at least $85 \%$ of total days from the 6-month diet study. Three subjects did not meet the adherent criteria but were able to objectively comply with a $\mathrm{KD}^{\mathrm{MAD}}$ for a median of 3.5 months.

\section{Safety of KD ${ }^{M A D}$ in relapsing MS}

A single subject reported sensory symptoms that raised concern for a clinical relapse; however, after obtaining a thorough history and repeat imaging of the brain and spinal cord (that demonstrated no new or enlarging lesions), these symptoms were considered unlikely to represent an MS relapse by the treating neurologist. One-third $(n=6)$ of subjects denied any side effects on $\mathrm{KD}^{\mathrm{MAD}}$. The most common side effects reported by the remaining subjects included intermittent constipation $(n=5)$, menstrual irregularities $(n=4)$, and diarrhea $(n=3)$.
Table 1 Clinical characteristics of study subjects

\begin{tabular}{ll}
\hline Age, median years (range) & $38(15-50)$ \\
\hline Sex & $17(85)$ \\
\hline Female, $\mathbf{n}(\%)$ & $18(90)$ \\
\hline Race & $2(10)$ \\
\hline White, $\mathbf{n}(\%)$ & $1(5)$ \\
\hline BMI category & $5(25)$ \\
\hline Normal weight, $\mathbf{n}(\%)$ & $14(70)$ \\
\hline Overweight, $\mathbf{n}(\%)$ & $9.5 \pm 5.4$ \\
\hline Obese, $\mathbf{n}(\%)$ & $6.4 \pm 3.3$ \\
\hline MS disease duration, mean years ( \pm SD) & $2.0(1.0-4.0)$ \\
\hline Time since last clinical relapse, mean years $( \pm$ SD) & $2.2 \pm 1.1$ \\
\hline Baseline EDSS score, median score (range) & $\mathbf{n}(\%)$ \\
\hline $\begin{array}{l}\text { No. of previous disease-modifying therapies } \\
\text { attempted, mean ( } \pm \text { SD) }\end{array}$ & \\
\hline Current disease-modfying & \\
\hline
\end{tabular}

Current disease-modifying therapy, n (\%)

\begin{tabular}{lc}
\hline Interferon beta-1a & $4(20)$ \\
\hline Glatiramer acetate & $3(15)$ \\
\hline Teriflunomide & $2(10)$ \\
\hline Dimethyl fumarate & $4(20)$ \\
\hline Fingolimod & $3(15)$ \\
\hline Natalizumab & $3(15)$ \\
\hline Rituximab & $1(5)$ \\
\hline Subjects with previous diet attempt(s), $\mathbf{n}(\%)$ & $13(65)$ \\
\hline
\end{tabular}

$\mathrm{BMI}=$ body mass index; EDSS $=$ Expanded Disability Status Scale.

As an additional safety metric, all subjects had an MRI of the brain with contrast performed before study start and then again at 6 months from diet start $(n=18)$. No subject was found to have new or enlarging FLAIR/T2 lesions at 6 months. Likewise, no subject was found to have new CELs at the 6-month scan.

\section{Anthropometric outcomes}

Anthropometric outcome measures are reported in table 2. Using the intention-to-treat approach, subjects experienced a mean reduction of 3 points in BMI, which was maintained at 3 - and 6-month assessments $(p<0.0001)$. From the study cohort, 7 subjects (all of whom met the study compliance criteria) changed Centers for Disease Control and Prevention BMI categories between baseline assessment and 6 months on diet: obese to normal weight $(n=2)$, obese to overweight $(\mathrm{n}=3)$, and overweight to normal weight $(\mathrm{n}=$ 2 ). Waist circumference also significantly decreased on diet at $3(p \leq 0.0001)$ and 6 months $(p=0.0004)$. Over 6 
Table 2 Intention-to-treat analysis of outcome measures pre- and post-KD ${ }^{M A D}$ intervention

\begin{tabular}{|c|c|c|c|c|c|}
\hline & Baseline values & $\begin{array}{l}\Delta \text { change at } \\
3 \text { months }(n=19)\end{array}$ & $p$ Value & $\begin{array}{l}\Delta \text { change at } \\
6 \text { months }(n=18)\end{array}$ & $p$ Value \\
\hline \multicolumn{6}{|l|}{ Anthropometric measures } \\
\hline Body mass index (BMI) & $34.1 \pm 6.9$ & $-3.0 \pm 1.6$ & $<0.0001$ & $-3.0 \pm 2.2$ & $<0.0001$ \\
\hline Waist circumference, $\mathrm{cm}$ & $106.4 \pm 14.0$ & $-8.5 \pm 4.8$ & $<0.0001$ & $-9.7 \pm 8.9$ & 0.0004 \\
\hline \multicolumn{6}{|l|}{ BOD POD assessment } \\
\hline Fat mass, kg & $42.5 \pm 16.6$ & - & - & $-7.0 \pm 5.3$ & $<0.0001$ \\
\hline Fat-free mass, kg & $51.1 \pm 10.8$ & - & - & $-1.2 \pm 2.4$ & 0.048 \\
\hline Resting metabolic rate, kcal/d & $1,510.3 \pm 309.5$ & - & - & $-57.8 \pm 71.3$ & 0.005 \\
\hline \multicolumn{6}{|l|}{ Subject-reported outcomes } \\
\hline Beck Depression Inventory & $7.2 \pm 5.8$ & $-3.4 \pm 3.2$ & 0.0002 & $-2.9 \pm 3.6$ & 0.003 \\
\hline Total Modified Fatigue Impact Scale & $34.1 \pm 17.1$ & $-12.9 \pm 13.2$ & 0.0005 & $-12.3 \pm 14.4$ & 0.002 \\
\hline Physical subscale & $15.8 \pm 8.9$ & $-6.6 \pm 6.5$ & 0.0003 & $-5.8 \pm 8.6$ & 0.01 \\
\hline Cognitive subscale & $15.8 \pm 8.3$ & $-5.3 \pm 6.2$ & 0.002 & $-5.6 \pm 5.8$ & 0.0008 \\
\hline Social subscale & $2.4 \pm 1.7$ & $-1.0 \pm 1.3$ & 0.003 & $-0.9 \pm 1.8$ & 0.04 \\
\hline \multicolumn{6}{|l|}{ Clinical outcome measures } \\
\hline Expanded Disability Status Scale & $2.2 \pm 0.9$ & - & - & $-0.8 \pm 0.6$ & $<0.0001$ \\
\hline \multicolumn{6}{|l|}{ MS Functional Composite } \\
\hline Timed 25-foot walk, s & $5.5 \pm 2.3$ & - & - & $+0.3 \pm 0.8$ & 0.15 \\
\hline 9-Hole Peg Test dominant, s & $20.6 \pm 3.5$ & - & - & $-0.4 \pm 1.7$ & 0.30 \\
\hline 9-Hole Peg Test nondominant, s & $22.9 \pm 8.3$ & - & - & $-1.0 \pm 1.3$ & 0.006 \\
\hline Paced Auditory Serial Addition Test (number correct) & $45.5 \pm 9.8$ & - & - & $+1.2 \pm 5.3$ & 0.36 \\
\hline Symbol Digit Modalities Test (number correct) & $59.5 \pm 11.1$ & - & - & $+1.1 \pm 5.8$ & 0.45 \\
\hline 6-minute walk, feet & $1,652 \pm 397$ & - & - & $+56 \pm 123$ & 0.07 \\
\hline
\end{tabular}

All results within this table represent mean \pm SDs. $\Delta$ change $=$ mean 3- or 6-month value - mean baseline value. Bolded $p$ values are statistically significant.

months, the resting metabolic rate, as measured by BOD POD, was significantly reduced on diet $(p=0.005)$.

\section{Subject-reported and clinical outcome measures}

Significant improvements in subject-reported total fatigue scores at 3 months $(p=0.0005)$ and 6 months $(p=0.002)$ were noted. Benefits were seen across all 3 MFIS subscales: physical, cognitive, and psychosocial. Before diet, 3 subjects met the criteria for mood disturbance or depression on the BDI. Only 1 subject met the BDI criteria for mood disturbance at 3 and 6 months on diet. Significant reductions in raw BDI scores were noted at $3(p=0.0002)$ and 6 months $(p=0.003)$. Change in fatigue and depression scores from baseline to 3 and 6 months on diet is illustrated in figure 1.

EDSS scores significantly improved $(p<0.0001)$ between baseline and 6 months on diet, primarily because of improvements on bowel/bladder and sensory functional systems. In addition, there was no worsening on measures of lower limb functioning (6-minute walk, T25FW), upper limb functioning (9HPT), or cognition/attention (PASAT, SDMT). In fact, a significant improvement was noted on the 9HPT with the nondominant hand $(p=0.006)$ at 6 months.

\section{Laboratory outcomes}

Laboratory outcome data are presented in table 3 . No subject had clinically relevant or significant changes in electrolytes, bicarbonate levels, liver function testing, or glucose levels from baseline to 3 or 6 months on diet. Although a trend toward higher 25-hydroxyvitamin D levels on diet was noted, this was not statistically significant. Fasting insulin and hemoglobin Alc levels were significantly decreased at both 3 and 6 months on diet. Lipid profiles showed a significant increase in LDL and cholesterol at 3 months, although this increase declined at 6 months and was no longer significant. A significant decrease in triglyceride levels was noted at 6 
Figure 1 Subject-reported outcomes for subjects compliant to KD MAD at $3(n=19)$ and 6 months $(n=15)$ for depression

A

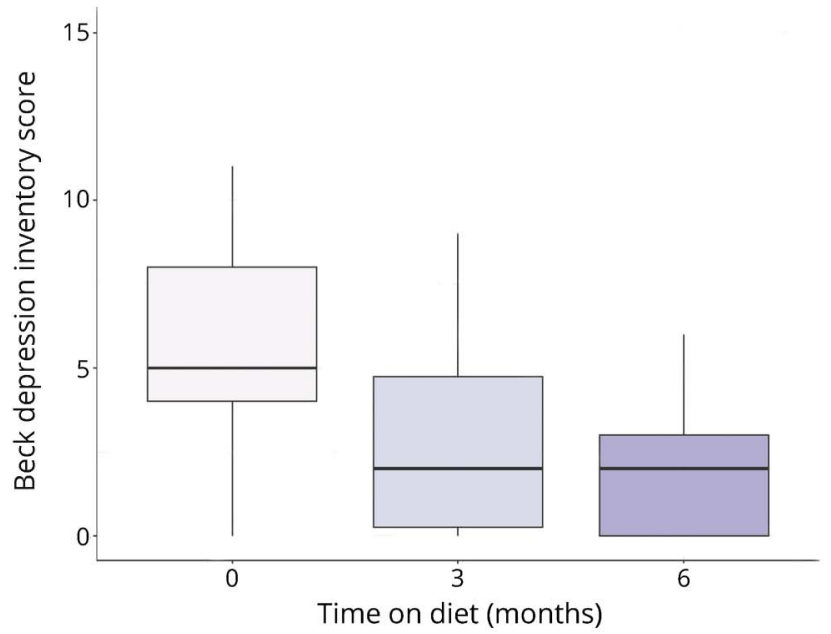

B

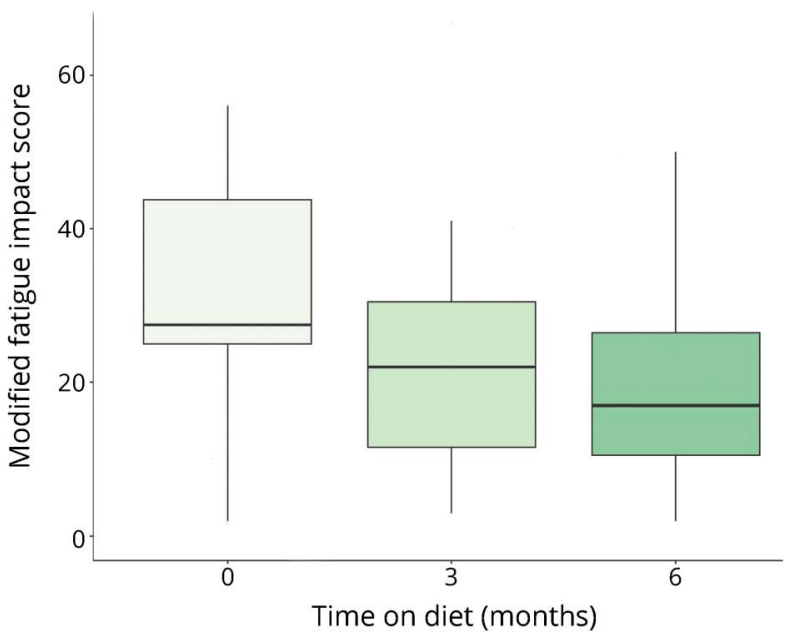

(A) Depression scores as a function of time adhering to a modified KD (as assessed by the Beck Depression Inventory) and (B) fatigue levels as a function of time adhering to a modified KD fatigue (as assessed by the Modified Fatigue Impact Scale). Boxplots demonstrate the median and interquartile range. Whiskers represent the range. KD = ketogenic diet.

months on diet. Notably, a significant decrease in free carnitine levels was seen at both 3 and 6 months on $\mathrm{KD}^{\mathrm{MAD}}$.

Fasting serologic leptin was significantly decreased at 3 months on $\mathrm{KD}^{\mathrm{MAD}}(p<0.0001)$ and trended toward significance at 6 months when using intention-to-treat analysis. The relative reduction in leptin was not significantly correlated with the relative reduction in BMI $(r=0.46 \mathrm{n}=19 ; p=0.06)$. There was a nonsignificant trend for increasing serologic adiponectin levels on diet. The change in serologic leptin and adiponectin from baseline to 3 and 6 months on diet is depicted in figure 2 .

\section{Per-protocol analysis for compliant subjects}

Data were secondarily analyzed using a per-protocol approach (table e-1, links.lww.com/NXI/A110 and table e-2, links.lww. com/NXI/A111). When using this approach, the measures

Table 3 Intention-to-treat analysis of laboratory measures pre- and post-KD ${ }^{\mathrm{MAD}}$ intervention

\begin{tabular}{|c|c|c|c|c|c|}
\hline & Baseline & $\begin{array}{l}\Delta \text { change at } \\
3 \text { months }(n=19)\end{array}$ & $p$ Value & $\begin{array}{l}\Delta \text { change at } \\
6 \text { months }(n=17)\end{array}$ & $p$ Value \\
\hline \multicolumn{6}{|l|}{ Insulin resistance } \\
\hline Insulin, uIU/mL & $15.3 \pm 10.6$ & $-6.8 \pm 9.1$ & 0.005 & $-5.7 \pm 9.1$ & 0.02 \\
\hline Hemoglobin $A_{1} c, \%$ & $5.4 \pm 0.6$ & $-0.2 \pm 0.3$ & 0.005 & $-0.13 \pm 0.26$ & 0.049 \\
\hline \multicolumn{6}{|l|}{ Lipid profiles } \\
\hline Triglycerides, mg/dL & $125 \pm 47$ & $-19 \pm 46$ & 0.09 & $-21.3 \pm 38.5$ & 0.03 \\
\hline Low-density lipoprotein, mg/dL & $135 \pm 43$ & $+22 \pm 28$ & 0.003 & $+11.9 \pm 31.4$ & 0.13 \\
\hline High-density lipoprotein, mg/dL & $54 \pm 12$ & $-1 \pm 10$ & 0.58 & $+2.7 \pm 11.0$ & 0.31 \\
\hline Cholesterol, mg/dL & $210 \pm 46$ & $+17 \pm 31$ & 0.03 & $+11.1 \pm 35.1$ & 0.20 \\
\hline 25-Hydroxyvitamin D, ng/mL & $44 \pm 20$ & $+7 \pm 16$ & 0.06 & $+6.1 \pm 12.6$ & 0.06 \\
\hline Free carnitine, $\mathrm{nmol} / \mathrm{mL}$ & $36 \pm 9$ & $-5 \pm 7$ & 0.004 & $-8.9 \pm 8.3$ & 0.0003 \\
\hline \multicolumn{6}{|l|}{ Adipokines } \\
\hline Leptin, ng/mL & $22.9 \pm 11.8$ & $-8.9 \pm 6.8$ & $<0.0001$ & $-4.9 \pm 9.6$ & 0.06 \\
\hline Adiponectin, $\mathrm{mcg} / \mathrm{mL}$ & $10.1 \pm 4.3$ & $+0.7 \pm 2.7$ & 0.25 & $+1.4 \pm 3.6$ & 0.12 \\
\hline
\end{tabular}

All results within this table represent mean \pm SDs. $\Delta$ change $=$ mean 3- or 6-month value - mean baseline value. Bolded $p$ values are statistically significant. 
Figure 2 Change in baseline fasting serologic adipokine levels for compliant subjects at $3(n=19)$ and 6 months $(n=15)$ on KD MAD

A

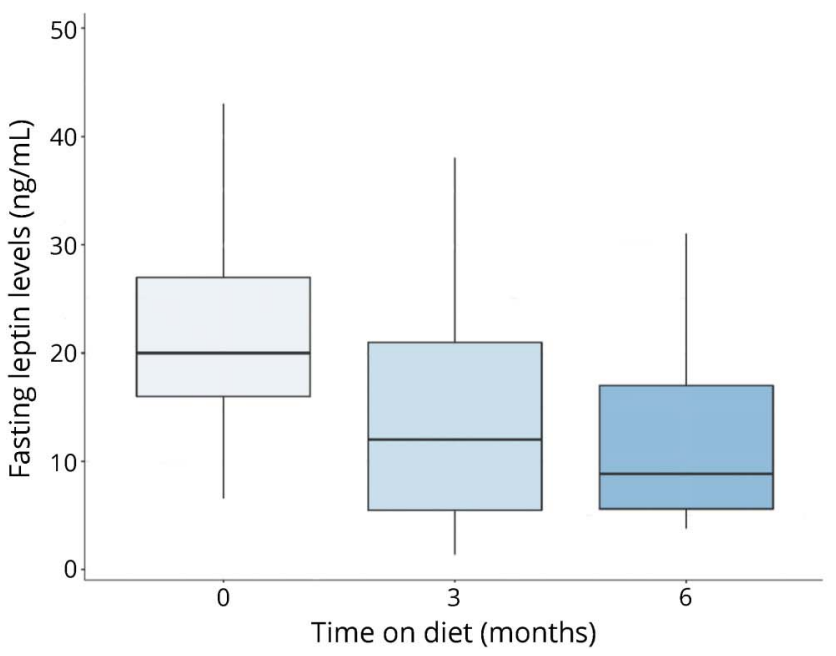

B

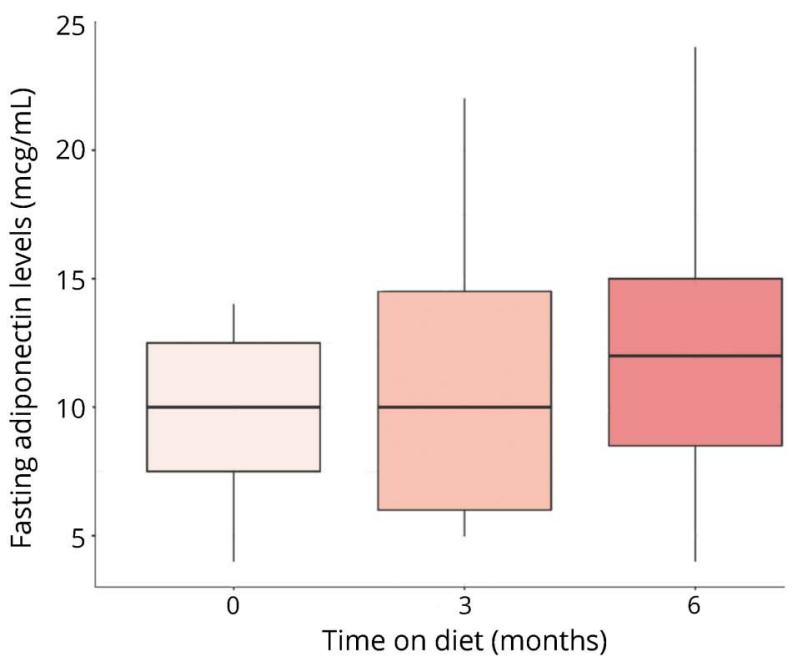

(A) Serologic leptin as function of time adhering to modified KD and (B) serologic adiponectin as a function of time adhering to modified KD. Boxplots demonstrate the median and interquartile range. Whiskers represent the range. KD = ketogenic diet.

demonstrating significance with intention-to-treat analysis remained strongly significant. Furthermore, serologic leptin was significantly different from baseline at both $3(p<0.0001)$ and 6 months $(p=0.03)$.

\section{Post-diet study outcomes}

Fifteen subjects (75\%) returned for the final 3-month visit following completion of the diet study. The remaining 5 subjects were lost to follow-up: 3 of these subjects met the compliance criteria for the 6-month trial and 2 were noncompliant subjects. Of the 15 subjects who returned for followup, 2 did not meet the compliance criteria for the 6-month diet protocol. From all subjects attending this post-study follow-up visit, $4(27 \%)$ continued to adhere to a strict $\mathrm{KD}^{\mathrm{MAD}}$, and 9 subjects $(60 \%)$ reported eating a lower carbohydrate diet but not adhering as strictly to the tenets of the $\mathrm{KD}^{\mathrm{MAD}}$. The remaining 2 subjects (13\%) reported returning to their pre-study dietary habits. At this follow-up visit, subjects continued to have significant weight lost from baseline (prediet) in addition to persistent benefits on fatigue (table e-3, links.lww.com/NXI/A112).

\section{Discussion}

Dietary interventions are rapidly gaining popularity within the MS community, ${ }^{2}$ and recently, patterns of dietary intake have been directly linked with disability in MS. ${ }^{3}$ In particular, diets that mimic a fasting state (i.e., KDs) have potential for multimodal benefits in an MS population, given the documented properties of these diets in reducing serologic inflammation, providing a more efficient central energy source, and by upregulation of antioxidant pathways. Given these potential benefits on MS disease, our group took the first steps toward elucidating the benefits of KDs within a human MS cohort by studying the safety and tolerability of a $\mathrm{KD}^{\mathrm{MAD}}$ in diseasestable subjects with RRMS. Our data support the short-term safety of these diets for patients with MS in terms of clinical, radiologic, and serologic measurements. Furthermore, our data provide evidence on the feasibility of studying these diets within an MS cohort, with $95 \%$ able to comply for 3 months and 3 quarters of all subjects able to comply for 6 months of diet intervention. Of note, compliance in our study exceeds compliance estimates from the current epilepsy literature. ${ }^{18-20}$ The majority of our study population maintained their weight loss and several continued to apply $\mathrm{KD}^{\mathrm{MAD}}$ principles toward food selection in the 3 months following study completion.

From all safety laboratory parameters followed, there was a noted transient increase in LDL and total cholesterol that stabilized by 6 months on diet. Subjects benefitted from a reduction in triglyceride levels at 6 months on diet therapy. Free carnitine levels significantly declined on diet at 3 and 6 months and are a known side effect of a KD. We recommend fractionated carnitine levels be followed on KDs and supplementation be initiated if deficiencies arise.

Based on our study in a human MS population, the $\mathrm{KD}^{\mathrm{MAD}}$ provided significant benefits to subjects throughout the study with a significant reduction in several anthropometric measures - including BMI, fat mass, waist circumference, and resting metabolic rate. Subject-reported measures of fatigue and depression also improved on diet. Although the study was not designed nor powered to evaluate the effect of diet on MS, we did note a significant decrease in EDSS scores at 6 months on diet-secondary to improved sensory and bowel/bladder 
symptoms. Our results confirm a significant relationship between $\mathrm{KD}$ and declining serum leptin levels at 3 and 6 months for those subjects adhering to the diet. Importantly, we did not see a strong correlation between BMI and leptin levels, suggesting that the KD's influence on leptin regulation is likely multimodal and not just secondary to its ability to induce a reduction in adiposity. Given leptin's role as a proinflammatory adipokine, this suggests one immunologic pathway in which these diets may benefit MS disease.

A limitation of this study includes the lack of a control group. In addition, our study likely recruited a motivated population (including a large proportion of overweight/obese subjects), which could affect the compliance rates reported. By including a largely overweight/obese population, our study results may not be generalizable to patients with MS of normal weight. In addition, our cohort likely exhibited heightened adherence secondary to our compliance approach, which required subjects to provide daily photographic evidence of urinary ketones. On the other hand, this more objective compliance approach represents a specific strength of this studycompared with previous diet studies that rely primarily on dietary recall. Although serologic BHB levels provide a more accurate reflection of ketosis, ${ }^{21}$ this method of compliance testing is not feasible for daily assessment primarily secondary to the high cost of blood ketone testing strips in addition to the discomfort associated with daily fingersticks. Finally, our inclusion of only subjects with relapsing, clinically and radiographically stable MS prohibits generalization to progressive MS subtypes or to patients with actively relapsing MS.

Our results provide evidence supporting the safety and tolerability of KDs in a relapsing MS population. These diets appear to provide clinical benefits on common MS comorbidities such as fatigue and depression. This early-phase study was not designed to study the efficacy of a $\mathrm{KD}^{\mathrm{MAD}}$ on MS, and thus, future next steps include a prospective randomized, casecontrol study to define the effect of $\mathrm{KD}^{\mathrm{MAD}}$ on disease control.

\section{Classification of evidence}

This study provides Class IV evidence that the modified Atkins diet is safe and well tolerated in subjects with relapsing MS, with benefits on fatigue, depression, and serologic proinflammatory adipokine levels.

\section{Acknowledgment}

The authors thank Denise Bruen, NP, for her assistance in the recruitment of our study population.

\section{Study funding}

This study was funded through private foundational funding provided by the ziMS Foundation.

\section{Disclosure}

J.N. Brenton has served as a consultant for Novartis. B. Banwell has served as a consultant and speaker for Novartis. She also serves as a nonremunerated advisor to Biogen IDEC, Sanofi, and Teva Neuroscience. She has given a lecture for Medscape. A.G.C. Bergqvist has served as a consultant for Nutricia North America, Dannon, Vitaflo, and the Charlie Foundation. D. Lehner-Gulotta, L. Gampper, E. Leytham, and R. Coleman report no disclosures. M.D. Goldman has served as a consultant for ADAMAS, Celgene, ENDECE, EMD Serono, Novartis Pharmaceuticals, Sanofi Genzyme, and Teva Pharmaceuticals. She has received research funding from Biogen Idec, Novartis Pharmaceuticals, National MS Society, and MedDay Pharmaceuticals. Full disclosure form information provided by the authors is available with the full text of this article at Neurology.org/NN.

\section{Publication history}

Received by Neurology: Neuroimmunology \& Neuroinflammation December 9, 2018. Accepted in final form March 5, 2019.

Appendix Authors

\begin{tabular}{|c|c|c|c|}
\hline Name & Location & Role & Contribution \\
\hline $\begin{array}{l}\text { J. Nicholas } \\
\text { Brenton, } \\
\text { MD }\end{array}$ & $\begin{array}{l}\text { University of } \\
\text { Virginia, } \\
\text { Charlottesville }\end{array}$ & Author & $\begin{array}{l}\text { Designed and } \\
\text { conceptualized the study; } \\
\text { analyzed the data; major } \\
\text { role in the acquisition of } \\
\text { data; and drafted the } \\
\text { manuscript for intellectual } \\
\text { content }\end{array}$ \\
\hline
\end{tabular}

\begin{tabular}{|c|c|c|c|}
\hline $\begin{array}{l}\text { Brenda } \\
\text { Banwell, } \\
\text { MD }\end{array}$ & $\begin{array}{l}\text { Children's } \\
\text { Hospital of } \\
\text { Philadelphia, } \\
\text { Philadelphia }\end{array}$ & Author & $\begin{array}{l}\text { Helped design and } \\
\text { conceptualize the study } \\
\text { and revised the } \\
\text { manuscript for } \\
\text { intellectual content }\end{array}$ \\
\hline $\begin{array}{l}\text { A.G. } \\
\text { Christina } \\
\text { Bergqvist, } \\
\text { MD }\end{array}$ & $\begin{array}{l}\text { Children's } \\
\text { Hospital of } \\
\text { Philadelphia, } \\
\text { Philadelphia }\end{array}$ & Author & $\begin{array}{l}\text { Helped design and } \\
\text { conceptualize the study and } \\
\text { revised the manuscript for } \\
\text { intellectual content }\end{array}$ \\
\hline $\begin{array}{l}\text { Diana } \\
\text { Lehner- } \\
\text { Gulotta, } \\
\text { RDN }\end{array}$ & $\begin{array}{l}\text { University of } \\
\text { Virginia, } \\
\text { Charlottesville }\end{array}$ & Author & $\begin{array}{l}\text { Helped design and } \\
\text { conceptualize the study; } \\
\text { major role in the acquisition } \\
\text { of data; and revised the } \\
\text { manuscript for intellectual } \\
\text { content }\end{array}$ \\
\hline
\end{tabular}

\begin{tabular}{llll}
\hline $\begin{array}{l}\text { Lauren } \\
\text { Gampper }\end{array}$ & $\begin{array}{l}\text { University of } \\
\text { Virginia, } \\
\text { Charlottesville }\end{array}$ & Author & $\begin{array}{l}\text { Major role in the acquisition } \\
\text { of data }\end{array}$ \\
\hline $\begin{array}{l}\text { Emily } \\
\text { Leytham }\end{array}$ & $\begin{array}{l}\text { University of } \\
\text { Virginia, } \\
\text { Charlottesville }\end{array}$ & Author & $\begin{array}{l}\text { Major role in the acquisition } \\
\text { of data }\end{array}$ \\
\hline $\begin{array}{l}\text { Rachael } \\
\text { Coleman }\end{array}$ & $\begin{array}{l}\text { University of } \\
\text { Virginia, } \\
\text { Charlottesville }\end{array}$ & Author & $\begin{array}{l}\text { Major role in the acquisition } \\
\text { of data }\end{array}$ \\
\hline $\begin{array}{l}\text { Myla D } \\
\text { Goldman, } \\
\text { MD }\end{array}$ & $\begin{array}{l}\text { University of } \\
\text { Virginia, } \\
\text { Charlottesville }\end{array}$ & Author & $\begin{array}{l}\text { Helped design and } \\
\text { conceptualize the } \\
\text { study and revised the } \\
\text { manuscript for }\end{array}$ \\
& intellectual content \\
\hline
\end{tabular}




\section{References}

1. Hedstrom AK, Olsson T, Alfredsson L. High body mass index before age 20 is associated with increased risk for multiple sclerosis in both men and women. Mult Scler 2012;18:1334-1336.

2. Brenton JN, Goldman MD. A study of dietary modification: perceptions and attitudes of patients with multiple sclerosis. Mult Scler Relat Disord 2016;8:54-57.

3. Fitzgerald KC, Tyry T, Salter A, et al. Diet quality is associated with disability and symptom severity in multiple sclerosis. Neurology 2018;90:e1-e11.

4. Milder JB, Liang LP, Patel M. Acute oxidative stress and systemic Nrf2 activation by the ketogenic diet. Neurobiol Dis 2010;40:238-244.

5. Sullivan PG, Rippy NA, Dorenbos K, Concepcion RC, Agarwal AK, Rho JM. The ketogenic diet increases mitochondrial uncoupling protein levels and activity. Ann Neurol 2004;55:576-580.

6. Bough KJ, Rho JM. Anticonvulsant mechanisms of the ketogenic diet. Epilepsia 2007; 48:43-58.

7. Achanta LB, Rae CD. Beta-hydroxybutyrate in the brain: one molecule, multiple mechanisms. Neurochem Res 2017;42:35-49.

8. Ruskin DN, Kawamura M, Masino SA. Reduced pain and inflammation in juvenile and adult rats fed a ketogenic diet. PLoS One 2009;4:e8349.

9. Dupuis N, Curatolo N, Benoist JF, Auvin S. Ketogenic diet exhibits anti-inflammatory properties. Epilepsia 2015;56:e95-e98.

10. Kim DY, Hao J, Liu R, Turner G, Shi FD, Rho JM. Inflammation-mediated memory dysfunction and effects of a ketogenic diet in a murine model of multiple sclerosis. PLoS One 2012;7:e35476.

11. Ni FF, Li CR, Liao JX, et al. The effects of ketogenic diet on the Th17/Treg cells imbalance in patients with intractable childhood epilepsy. Seizure 2016;38:17-22.
12. Shen $\mathrm{Y}$, Kapfhamer D, Minnella AM, et al. Bioenergetic state regulates innate inflammatory responses through the transcriptional co-repressor CtBP. Nat Commun 2017;8:624.

13. Youm YH, Nguyen KY, Grant RW, et al. The ketone metabolite beta-hydroxybutyrate blocks NLRP3 inflammasome-mediated inflammatory disease. Nat Med 2015;21: 263-269.

14. Yang X, Cheng B. Neuroprotective and anti-inflammatory activities of ketogenic diet on MPTP-induced neurotoxicity. J Mol Neurosci 2010;42:145-153.

15. Goldberg EL, Asher JL, Molony RD, et al. Beta-hydroxybutyrate deactivates neutrophil NLRP3 inflammasome to relieve gout flares. Cell Rep 2017;18:2077-2087.

16. Polman CH, Reingold SC, Banwell B, et al. Diagnostic criteria for multiple sclerosis: 2010 revisions to the McDonald criteria. Ann Neurol 2011;69:292-302.

17. Center for Disease Control. Healthy Weight. 2015. Available at: www.cdc.gov/ healthyweight/assessing/bmi/childrens_bmi/about_childrens_bmi.html. Accessed May 19, 2016.

18. Kossoff EH, McGrogan JR, Bluml RM, Pillas DJ, Rubenstein JE, Vining EP. A modified Atkins diet is effective for the treatment of intractable pediatric epilepsy. Epilepsia 2006;47:421-424.

19. Cervenka MC, Henry BJ, Felton EA, Patton K, Kossoff EH. Establishing an adult epilepsy diet center: experience, efficacy and challenges. Epilepsy Behav 2016;58: 61-68.

20. Chen W, Kossoff EH. Long-term follow-up of children treated with the modified Atkins diet. J Child Neurol 2012;27:754-758.

21. Gilbert DL, Pyzik PL, Freeman JM. The ketogenic diet: seizure control correlates better with serum beta-hydroxybutyrate than with urine ketones. J Child Neurol 2000; 15:787-790. 


\section{Neurology \\ Neuroimmunology \& Neuroinflammation}

Pilot study of a ketogenic diet in relapsing-remitting MS

J. Nicholas Brenton, Brenda Banwell, A.G. Christina Bergqvist, et al.

Neurol Neuroimmunol Neuroinflamm 2019;6;

DOI 10.1212/NXI.0000000000000565

This information is current as of April 12, 2019

\section{Updated Information \& Services}

References

Citations

Subspecialty Collections

Permissions \& Licensing

Reprints including high resolution figures, can be found at:

http://nn.neurology.org/content/6/4/e565.full.html

This article cites 20 articles, 0 of which you can access for free at: http://nn.neurology.org/content/6/4/e565.full.html\#\#ref-list-1

This article has been cited by 5 HighWire-hosted articles: http://nn.neurology.org/content/6/4/e565.full.html\#\#otherarticles

This article, along with others on similar topics, appears in the following collection(s):

Multiple sclerosis

http://nn.neurology.org//cgi/collection/multiple_sclerosis

Information about reproducing this article in parts (figures,tables) or in its entirety can be found online at:

http://nn.neurology.org/misc/about.xhtml\#permissions

Information about ordering reprints can be found online: http://nn.neurology.org/misc/addir.xhtml\#reprintsus

Neurol Neuroimmunol Neuroinflamm is an official journal of the American Academy of Neurology.

Published since April 2014, it is an open-access, online-only, continuous publication journal. Copyright

Copyright (C) 2019 The Author(s). Published by Wolters Kluwer Health, Inc. on behalf of the American

Academy of Neurology.. All rights reserved. Online ISSN: 2332-7812.

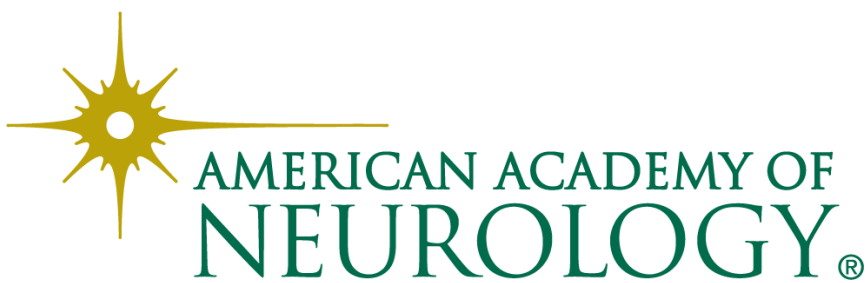

